\title{
THE BARRIER MAGNETIC SEPARATOR FOR THE TREATMENT OF WEAKLY MAGNETIC ORES: LABORATORY- SCALE INVESTIGATIONS AND INDUSTRIAL TESTS
}

\author{
A.M. TURKENICH ${ }^{\mathrm{a}, *}$, U.D. BARANOV ${ }^{\mathrm{b}}$ and A.V. RUDITSKY ${ }^{\mathrm{c}}$ \\ ${ }^{a}$ National Mining University of Ukraine, Karl Marks 19, 49000 Dnepropetrovsk, \\ Ukraine; ${ }^{\mathrm{b}}$ Volnogorsk State Mining and Metallurgical Plant (VSMMP), \\ 322550 Vilnogirsk, Ukraine; ${ }^{\mathrm{c}}$ Magnetic and Hydraulic Technologies Co., \\ 49005 Dnepropetrovsk, Ukraine
}

(Received 2 May 2002; Revised 9 July 2002; Accepted 12 July 2002)

The principle of action of the barrier separator for beneficiation of coarse weakly magnetic ores is described. New data of laboratory-scale investigations of beneficiation of manganese ore and mineral sands are introduced. The results of tests in the Volnogorsk State Mining and Metallurgical Plant (VSMMP) show high technological effectiveness and reliability of the experimental separator.

Keywords: Barrier magnetic separator; Induced magnetic roll separator; Manganese ore; Mineral sands

\section{INTRODUCTION}

High-intensity magnetic separation (HIMS) of weakly magnetic ores in roll and rotary magnetic separators includes attraction of magnetic particles at rolls or at grooved ferromagnetic plates and continuous removal of the attracted particles from the zone of a strong magnetic field for their further discharge in the magnetic product. In order to

\footnotetext{
${ }^{*}$ Corresponding author.
} 
facilitate this removal, the separators are equipped with complex and expensive rolls or rotors, drives and bearings. The utilization factor of the magnetic circuit of such separators is low because a considerable part of space between the poles is used only to transport magnetic particles from the zone of their attraction to the zone of their discharge. A considerable part of the total electrical power input into the separators is used not for the recovery of magnetic particles, but to rotate the rolls and rotors. For example, input power of the roll drives is $60-70 \%$ of the total input power of the separator [1]. The cost of these revolving devices, drives and bearings is more than $50 \%$ of total cost of a separator. In the case of a roll separator the material to be separated moves in narrow gaps between surfaces of the poles and rolls, which revolve with high velocity. It leads to intensive abrasion of the rolls by coarse material. This results in a change of their shape and further inevitable reduction of recovery of magnetic particle.

These disadvantages are absent in the barrier magnetic separator. Originally Frantz [2] developed such separator in the USA in 1936. It is a well-known laboratory-scale isodynamic separator. T. Wellington, the former President of S.G. Frantz Co., Inc, tried to develop this separator for industrial application. He did not succeed to remove the main obstacle, namely the clogging of the channels by magnetic particles, which are attracted to the walls. The barrier separators proposed by others as well as our own previous work failed to find industrial application for the same reasons. Nevertheless, the accumulated knowledge allowed us to find a possibility to overcome the main disadvantage of the barrier separators. The results of laboratory-scale investigations of such a method and industrial tests of the experimental barrier separator are described in this article.

\section{EXPERIMENTAL SECTION}

\section{Design and Principle of Action of the Laboratory-scale Barrier Separator}

A barrier magnetic separator consists of a magnetic circuit and inclined channels, which are placed in a gap between poles. The walls and bottoms of the channels have smooth surfaces. There are 
no mechanical obstacles in the way of movement of the separated material in the channels. Thanks to a special inner structure of the walls, the gradient of the magnetic field is directed from the bottom perpendicularly towards a stream of the separated material which moves inside of the channel. The region where the product of the magnetic field intensity and the gradient of the intensity is the greatest is positioned above the bottom and extends along its entire length. This is the region of the magnetic barrier. Magnetic forces of the magnetic barrier prevent magnetic particles from passing through this region towards the bottom of the channel under the action of gravity.

Figure 1 shows a vertical longitudinal section of channel 1 . It is mounted between poles 2 of the magnetic circuit of the separator. Material 3 to be separated is fed into channel 1 above the region of the magnetic barrier 4 (a gray line) along its length. Non-magnetic particles 5 pass through the magnetic barrier onto the bottom of the channel and slide down into bin 6 for the non-magnetic product. Magnetic particles 7 cannot penetrate the magnetic barrier and are not attracted to the walls of the channel. That is why they slide down above the magnetic barrier into the magnetic product bin 8 . Thus, thanks to the magnetic barrier a stream of magnetic and non-magnetic particles is separated.

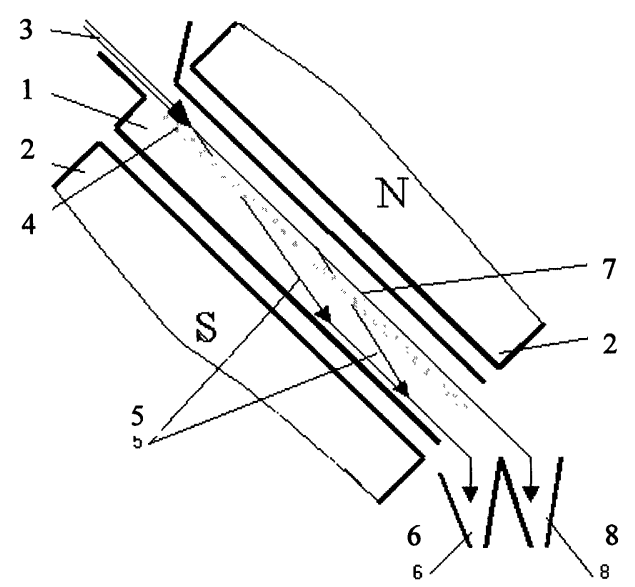

FIGURE 1 Schematic diagram of the matrix of the barrier separator. 
Figure 2 illustrates a distribution of the magnetic field intensity B (curve 1) in a plane of the vertical longitudinal section of the channel. Such a distribution takes place if the magnetic field intensity on the surface of the ceiling of the channel is $0.83 \mathrm{~T}$. Growth of the field intensity in the direction from the bottom to the ceiling of the channel results in the existence of the gradient of the field intensity ( $\operatorname{grad} B)$. The product of the magnetic field intensity and the gradient of the field intensity BgradB (curve 2) has a maximum. A region of this maximum is the region of the magnetic barrier. In our example BgradB is equal to $12.6 \mathrm{~T}^{2} / \mathrm{m}$. It means that particles with specific magnetic susceptibility $200 \times 10^{-8} \mathrm{~m}^{3} / \mathrm{kg}$ will be supported in the air by the barrier specific magnetic force, which is equal to $20 \mathrm{~N} / \mathrm{kg}$ or to twice the force of gravity.

Magnetic particles differ from each other by their magnetic susceptibilities. That is why they are dispersed under the action of magnetic forces along the height of the channel above the magnetic barrier. Particles, that have a higher magnetic susceptibility, move along magnetic barrier in the upper level of the flow. They do not bear on the lower particles. All of them float in the flow independently of each other, as they are supported by magnetic forces.

The non-magnetic particles begin to move down under the action of gravity as soon as they enter the separation channel. This movement takes place inside the suspended flow of magnetic particles.

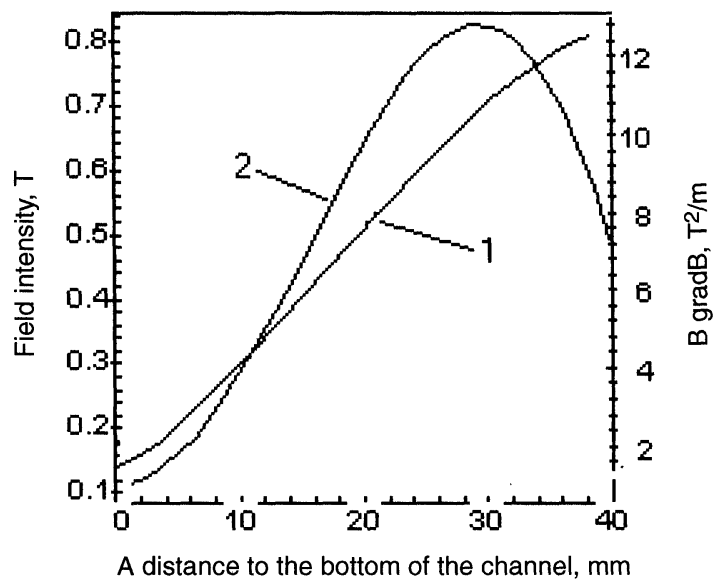

FIGURE 2 Distribution of magnetic field intensity $B$ and $B$ gradB along height of the channel $\mathrm{Bf}=0.8 \mathrm{~T}$. 


\section{Laboratory-scale Investigations}

Effectiveness of the process of barrier separation of manganese ore and mineral sands has been investigated. The laboratory-scale separator has a single channel, which is inclined at an angle $30^{\circ}$ with vertical. In all experiments the particles with increased magnetic susceptibility were removed from the sample of a material to be separated by scalping at low field intensity $(0.2 \mathrm{~T})$. The mass yield of the magnetic product was 0.7 to $1.5 \%$. Subsequently the material was treated in two stages of the barrier separation. The non-magnetic product from the first stage was separated in the second stage.

\section{Separation of the Manganese Ore}

A sample of the manganese ore in the size range $4 \mathrm{~mm}$ was treated in two stages of wet magnetic separation. The matrix had one channel $13 \mathrm{~mm}$ wide which is formed by walls $12 \mathrm{~mm}$ wide. The manganese ore was fed into the channel at the feed rate of $20 \mathrm{~g} / \mathrm{s}$. It corresponds to a throughput of $3.0 \mathrm{t} / \mathrm{h}$ per $1 \mathrm{~m}$ of the pole width of an industrial separator. An information about achieved results is in Table I.

The data show that the laboratory scale barrier separator, having $13 \mathrm{~mm}$ wide channel produces a high grade concentrate $42.4 \% \mathrm{Mn}$ at high recoveries of manganese in the magnetic product $(96.0 \%)$ and of free quartz in the non-magnetic product $(72.8 \%)$. The scalping magnetic separation completely excluded accumulation of particles of increased magnetic susceptibility on the walls of the channel.

The barrier separator allows to treat even very coarse ores at high capacity. For example, carbonate manganese ore in the size range

TABLE I The results of wet separation of the manganese ore

\begin{tabular}{lccccccc}
\hline \multirow{2}{*}{$\begin{array}{l}\text { Stage of } \\
\text { separation }\end{array}$} & \multirow{2}{*}{$\begin{array}{c}\text { Magnetic flux } \\
\text { density }(\mathrm{T})\end{array}$} & $\begin{array}{c}\text { Products of } \\
\text { separation }\end{array}$ & \multicolumn{5}{c}{ The results of separation \% } \\
\cline { 4 - 8 } & & & $\gamma$ & $\mathrm{Mn}$ & $\mathrm{SiO}_{2}$ & $\varepsilon_{\text {Mn }}$ & $\varepsilon_{\text {SiO2 }}$ \\
\hline \multirow{3}{*}{ 1st } & \multirow{2}{*}{0.75} & Feed & 100.0 & 32.6 & 28.7 & 100.0 & 100.0 \\
2nd & Magnetic & 49.0 & 42.7 & 9.8 & 64.3 & 16.7 \\
& 1.25 & Magnetic & 24.8 & 41.7 & 12.2 & 31.7 & 10.5 \\
& & Sum magnetic & 73.8 & 42.4 & 10.6 & 96.0 & 27.2 \\
& & Non-magnetic & 26.2 & 5.01 & 79.8 & 4.0 & 72.8 \\
\hline
\end{tabular}

where $\gamma$ is the mass yield into a product; $\mathrm{Mn}$ and $\mathrm{SiO}_{2}$ are the concentrations of manganese and free quartz in a product; $\varepsilon_{\mathrm{Mn}}$ and $\varepsilon_{\mathrm{SiO} 2}$ are the recovery of manganese and free quartz respectively in the separation products. 
$-10+6 \mathrm{~mm}$ was treated in two stages of dry separation. The width of the channel was $26 \mathrm{~mm}$. The ore was fed into the channel at the rate of $230 \mathrm{~g} / \mathrm{s}$ and the mass yield into the magnetic product was $52 \%$. The specific throughput of an industrial separator would thus be $18.0 \mathrm{t} / \mathrm{h}$ per $1 \mathrm{~m}$ of the pole width.

\section{Separation of Mineral Sands}

A flowsheet of the Volnogorsk Plant VSMMP includes gravity concentration of mineral sands and subsequent separation of heavy minerals from the gravity concentrate using successively high-tension and high-intensity magnetic separation. The conducting fraction of the high-tension separation includes magnetic ilmenite and nonmagnetic rutile. The effectiveness of barrier magnetic separation of this conducting fraction was investigated. The width of the channel was $10 \mathrm{~mm}$. Material to be separated was fed into the channel at a rate of $17 \mathrm{~g} / \mathrm{s}$. The specific throughput of an industrial separator will be in this case $3.0 \mathrm{t} / \mathrm{h}$ per $1 \mathrm{~m}$ of the pole width.

The achieved results are shown in Table II.

The laboratory-scale barrier separator exhibits a low loss of the nonmagnetic rutile in the magnetic product. The rutile concentration in the magnetic product of the barrier lab-scale separator is only $0.73 \%$, in comparison with 3 to $4 \%$ in the ilmenite concentrate of the roll separators of the VSMMP beneficiation plant. The recovery of ilmenite and ilmenite concentration in the magnetic products are by 6 and $1 \%$, respectively, higher than that achieved by the induced magnetic roll separator. As in the case of the manganese ore, the scalping magnetic separation completely eliminated accumulation of particles of increased magnetic susceptibility on the walls of the channel.

TABLE II The results of dry separation of the conducting fraction of mineral sands

\begin{tabular}{|c|c|c|c|c|c|c|c|}
\hline \multirow{2}{*}{$\begin{array}{l}\text { Stage of } \\
\text { separation }\end{array}$} & \multirow{2}{*}{$\begin{array}{c}\text { Magnetic flux } \\
\text { density }(\mathrm{T})\end{array}$} & \multirow{2}{*}{$\begin{array}{l}\text { Products of } \\
\text { separation }\end{array}$} & \multicolumn{5}{|c|}{ The results of separation $\%$} \\
\hline & & & $\gamma$ & Rutile & Ilmenite & $\varepsilon_{r u}$ & $\varepsilon_{i l}$ \\
\hline & & Feed & 100.0 & 23.6 & 66.4 & 100.0 & 100.0 \\
\hline 1st & 0.75 & Magnetic & 51.8 & 1.89 & 94.2 & 4.1 & 73.5 \\
\hline \multirow[t]{3}{*}{ 2nd } & 1.25 & Magnetic & 18.1 & 0.85 & 94.0 & 0.7 & 25.6 \\
\hline & & Total magnetic & 69.8 & 1.62 & 94.2 & 4.8 & 99.1 \\
\hline & & non-magnetic & 30.1 & 74.5 & 1.9 & 95.2 & 0.9 \\
\hline
\end{tabular}

where $\varepsilon_{\mathrm{ru}}$ and $\varepsilon_{\mathrm{il}}$ are the recovery of rutile and ilmenite respectively in the separation products. 


\section{An Industrial Test of the Experimental Barrier Magnetic Separator}

The process of barrier separation takes place in inclined matrices 1 as shown in Fig. 3. Each matrix consists of an array of the aforesaid channels. The matrices are placed between pole pieces 2 and horizontal bridge bars 3 (Figs. 3 and 4) of the magnetic circuit. Each matrix has 25 channels per $500 \mathrm{~mm}$ pole width. Dimensions of the channel are $10 \mathrm{~mm}$ width and $220 \mathrm{~mm}$ length.

There are two induced scalping rolls 4 placed above the matrices. They are used to remove particles of increased magnetic susceptibility. Diameter of each roll is $100 \mathrm{~mm}$ and the roll has a serrated profile. The magnetic field is induced by coils 5 and supplied to the rolls via ferromagnetic plates 6 .

The material to be separated is directed from feeder 7 into the gap between the roll and the ferromagnetic plate. The magnetic field intensity in the gap is $0.3 \mathrm{~T}$. Streams 8 of particles of higher magnetic susceptibility are thrown off the rolls into the magnetic product. The rest of material is introduced into the channels of the matrix for the barrier separation. Any of the obtained streams of particles, magnetic 9 or non-magnetic 10 , can be directed if necessary for further treatment at the next lower level of the barrier separator. The stream of magnetic

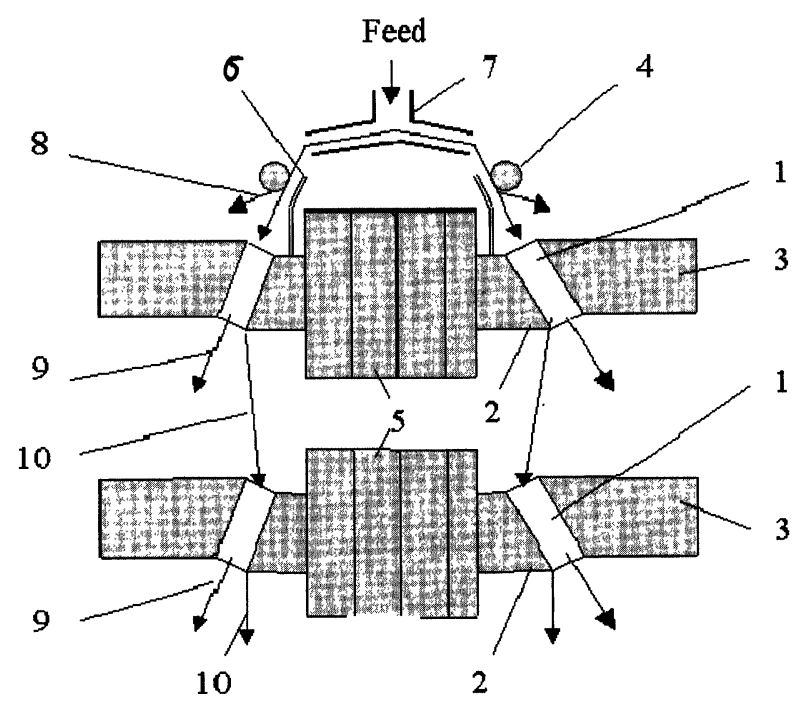

FIGURE 3 The schematic diagram of the barrier separator. 


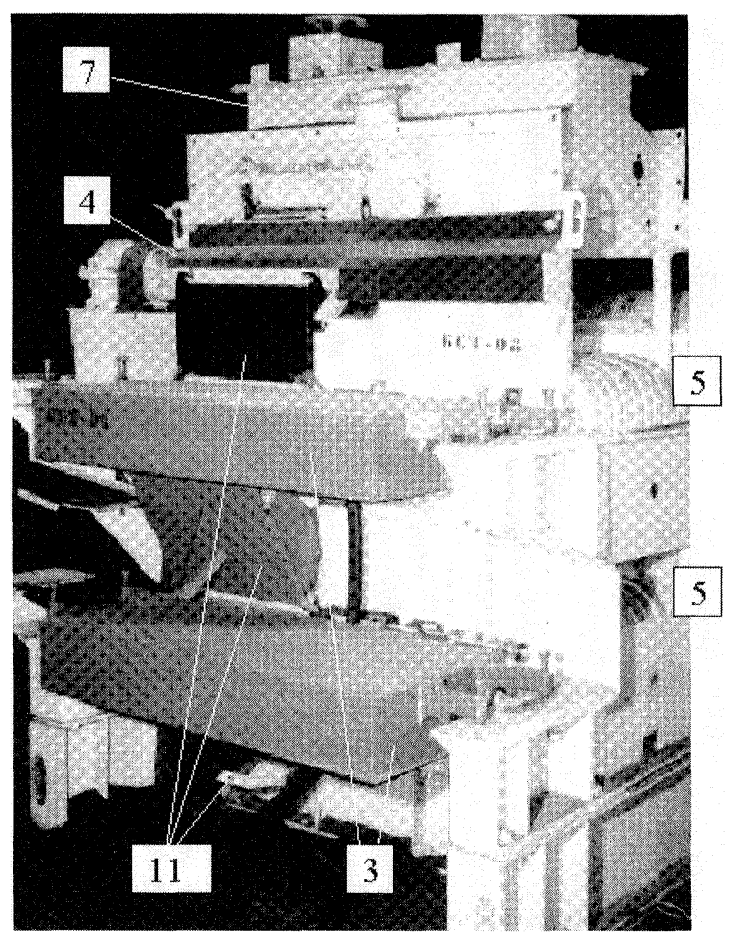

FIGURE 4 The principal view of the experimental barrier separator.

particles in our example is removed as the magnetic product, whereas the stream of non-magnetic particles is directed for further treatment. The non-magnetic particles move along chutes 11 (Fig. 4) from the upper level of separation to the lower one.

A picture of streams of magnetic particles, which flow out of channels, can be seen in Fig. 5. Every channel has two streams, which are pushed under the action of the horizontal component of the magnetic force between channels to the walls of the partitions 12 .

The test of the barrier separator took place in VSMMP. The conducting fraction of mineral sands was treated. It included rutile and ilmenite. The induced roll magnetic separators 2EVS of various modifications treat this conducting fraction. Disadvantages of these separators are the need to maintain the roll drives and high energy consumption by their drives [1]. Typical technological indications of commercial operation of 2EVS separators are shown in Table III. 


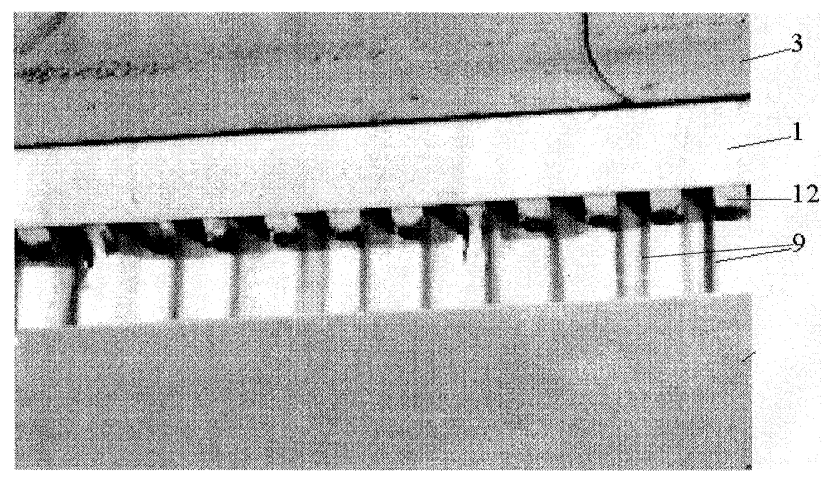

FIGURE 5 The view of the lower part of the matrix with jets of the magnetic product outside of the channels.

TABLE III Typical technological indicators of the induced magnetic roll separators 2EVS

\begin{tabular}{|c|c|c|c|c|c|c|c|}
\hline \multirow{2}{*}{$\begin{array}{l}\text { Average capacity } \\
\text { of one separator } \\
(\mathrm{t} / \mathrm{h} / \mathrm{m})\end{array}$} & \multirow{2}{*}{$\begin{array}{l}\text { Magnetic flux } \\
\text { density }(\mathrm{T})\end{array}$} & \multirow{2}{*}{$\begin{array}{l}\text { Products of } \\
\text { separation }\end{array}$} & \multicolumn{5}{|c|}{ The results of separation $\%$} \\
\hline & & & $\gamma$ & Rutile & Ilmenite & $\varepsilon_{r u}$ & $\varepsilon_{i l}$ \\
\hline \multirow{3}{*}{2} & \multirow{3}{*}{1.2} & Magnetic & 65.78 & 3.91 & 91.3 & 9.2 & 97.3 \\
\hline & & Non-magnetic & 34.22 & 76.63 & 4.91 & 90.8 & 2.7 \\
\hline & & Feed & 100.0 & 28.8 & 61.73 & 100.0 & 100.0 \\
\hline
\end{tabular}

The data show that the considerable cross-contamination of the separation products is taking place in VSMMP. The rutile content in the magnetic product is as high as $4 \%$ while ilmenite content in the rutile concentrate is as high as $5 \%$.

The test of the experimental barrier separator was carried out simultaneously with the test of a serial induced roll magnetic separator 2EVS-36/100, which was especially adjusted for this purpose. The obtained technological results are shown in Table IV.

The data show that the technological results of the barrier separator are better than those of the adjusted serial induced roll magnetic separator 2EVS-36/100 provided the throughput of the barrier separator is equal to that of the roll separators, as operated in VSMMP. The rutile content in magnetic product of the barrier separator is $0.82 \%$, which is by a factor of 2 less than the concentration in the magnetic product of the roll separator. The ilmenite content of the magnetic product of the barrier separator and the recovery of ilmenite in 
TABLE IV Technological results of comparative tests of the experimental barrier magnetic separator and the induced magnetic roll separator 2EVS-36/100

\begin{tabular}{|c|c|c|c|c|c|c|c|}
\hline \multirow{2}{*}{$\begin{array}{l}\text { Capacity } \\
(\mathrm{t} / \mathrm{h} / \mathrm{m})\end{array}$} & \multirow{2}{*}{$\begin{array}{c}\text { Magnetic flux } \\
\text { density (T) }\end{array}$} & \multirow{2}{*}{$\begin{array}{l}\text { Products of } \\
\text { separation }\end{array}$} & \multicolumn{5}{|c|}{ The results of separation $\%$} \\
\hline & & & $\gamma$ & Rutile & Ilmenite & $\varepsilon_{r u}$ & $\varepsilon_{i l}$ \\
\hline \multicolumn{8}{|c|}{ The experimental barrier magnetic separator } \\
\hline \multirow[t]{3}{*}{1.9} & 0.8 & Magnetic & 69.7 & 0.82 & 93.34 & 2.7 & 98.2 \\
\hline & & Non-magnetic & 30.3 & 67.21 & 3.87 & 97.3 & 1.8 \\
\hline & & Feed & 100.0 & 20.94 & 66.23 & 100.0 & 100.0 \\
\hline \multirow[t]{3}{*}{3.0} & 0.8 & Magnetic & 60.0 & 3.0 & 89.76 & 7.2 & 97.9 \\
\hline & & Non-magnetic & 40.0 & 57.85 & 2.89 & 92.8 & 2.1 \\
\hline & & Feed & 100.0 & 24.94 & 55.01 & 100.0 & 100.0 \\
\hline \multicolumn{8}{|c|}{ A serial specially adjusted induced roll magnetic separator $2 E V S-36 / 100$} \\
\hline \multirow[t]{3}{*}{2.1} & 1.2 & Magnetic & 67.26 & 1.53 & 91.9 & 4.6 & 96.9 \\
\hline & & Non-magnetic & 32.74 & 64.42 & 6.09 & 95.4 & 3.1 \\
\hline & & Feed & 100.0 & 23.33 & 61.34 & 100.0 & 100.0 \\
\hline
\end{tabular}

this product are also higher. The increase in the throughput of the barrier separator by a factor of 1.5 results in the increase of the rutile content of the magnetic product to $3 \%$. In spite of this all indicators of the barrier separator are better than average technological indicators of the VSMMP.

Accumulation of particles of increased magnetic susceptibility in the channels of the separator did not take place.

\section{CONCLUSION}

Industrial tests show that the barrier magnetic separator treats mineral sands with satisfactory effectiveness. The separator is simple and is easy to maintain. It allows to reduce power consumption by 60 to $70 \%$ compared to the induce electro-magnetic roll separators thanks to the absence of drivers for rotation of rolls in a magnetic field of high intensity.

\section{Acknowledgments}

We are very grateful to our technologist V.I. Dudnik, designer V.J. Koohar, workers and engineers of the VSMMP and the firm MHT for their skilled participation in fulfillment of laboratory-scale investigations, in design, construction and industrial testing of the experimental barrier separator. 


\section{References}

[1] A.M. Turkenich. A continuous barrier magnetic separator for the treatment of weakly magnetic ores. Magn. Electr. Sep., 4 (2001), 10.

[2] S.G. Frantz. Magnetic separation methods and means. US Patent 2,056, 426 (1936).

Alexander M. Turkenich: for biography see Magn. Electr. Sep., 8 (1996), 53.

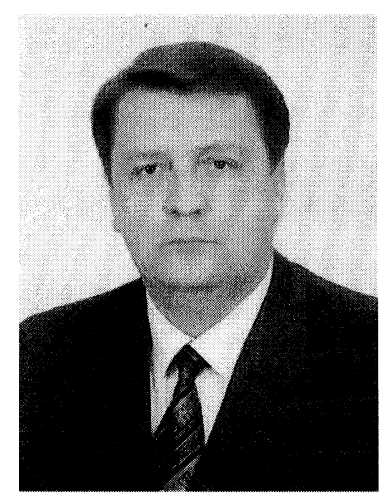

Uriy D. Baranov was born in 1962. After graduation from the Mining Institute in Dnepropetrovsk in 1986 he worked in a benefication plant in Yakutia. In 1991 he joined Vilnogorsk State Mining and Metallurgical Plant (VSMMP). In 2001 he was appointed as a Chief Engineer. At the end of the same year he was appointed Director General of VSMMP.

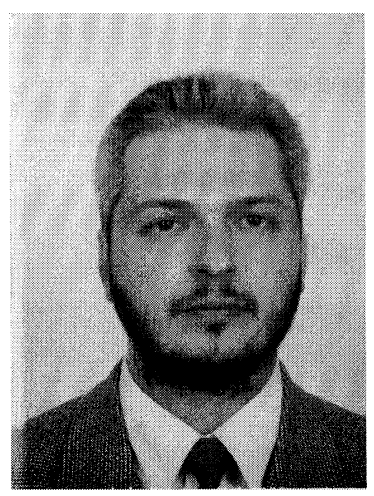

Arthur V. Ruditsky was born in 1963. He graduated from the Dnepropetrovsk State University in 1987. In 1991 joined Magnetic and Hydraulics Technologies company and in 1994 he was appointed as a Director of this enterprise. Mr. Ruditsky's area of activity is the design and manufacture of magnetic separators for beneficiation of magnetite and weakly magnetic ores. 